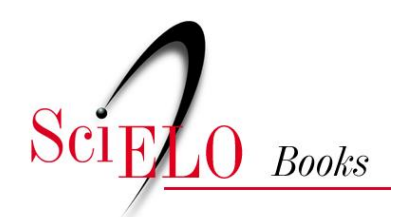

\title{
El proyecto misionero amazónico de los salesianos contradicciones y tensiones
}

\author{
Juan Bottasso
}

\section{SciELO Books / SciELO Livros / SciELO Libros}

BOTTASSO J. El proyecto misionero amazónico de los salesianos: contradicciones y tensiones. In: JUNCOSA BLASCO, J., and GARZÓN VERA, B., eds. Misiones, pueblos indígenas y la conformación de la Región Amazónica: actores, tensiones y debates actuales [online]. Quito: Editorial Abya-Yala, 2019, pp. 131-136. ISBN: 978-9978-10-494-1. https://doi.org/10.7476/9789978104941.0008.

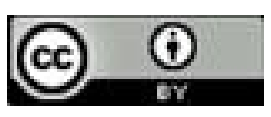

All the contents of this work, except where otherwise noted, is licensed under a Creative Commons Attribution 4.0 International license.

Todo o conteúdo deste trabalho, exceto quando houver ressalva, é publicado sob a licença Creative Commons Atribição 4.0.

Todo el contenido de esta obra, excepto donde se indique lo contrario, está bajo licencia de la licencia $\underline{\text { Creative }}$ Commons Reconocimento 4.0. 


\title{
El proyecto misionero amazónico de los salesianos: contradicciones y tensiones
}

\author{
Juan Bottasso, sdb \\ juanbottasso@yahoo.com
}

No hay que olvidar que los salesianos llegaron al Ecuador llamados por el Gobierno. Las negociaciones duraron años y terminaron con la estipulación de convenios firmados por ambas partes. El motivo principal para que fuera solicitada la presencia de los hijos de Don Bosco fue que se los consideró con capacidad para dar comienzo a la educación técnica en el país. Ellos aceptaron el reto y pusieron manos a la obra, fundando la institución que llegó a convertirse en lo que es hoy el Central Técnico, aun en pleno funcionamiento y gozando de mucho prestigio.

En un segundo momento, al crearse, por solicitud del mismo Gobierno, los Vicariatos Apostólicos del Oriente, se pidió a los salesianos que se hicieran cargo del Vicariato de Méndez y Gualaquiza, con el propósito específico de "civilizar a los bárbaros" que vivían en la región. Se trataba de la que es tal tuvieron lugar en Bogotá; obtuvo la licenciatura y el doctorado en Misionología en la Universidad Gregoriana, en Roma. 
ahora la provincia de Morona Santiago, habitada entonces casi exclusivamente por los Shuar. Había también otro motivo, declarado menos explícitamente: asegurar una presencia estable y organizada en el territorio, cuando el Estado aún estaba muy poco presente, mientras, con el auge cauchero, multitudes de aventureros de todo tipo estaban penetrando en la región desde Brasil y Perú, aprovechando la navegabilidad de los ríos.

Con el mismo fervor con que implementaron la educación técnica, los salesianos aceptaron el nuevo reto, pero encontraron una resistencia inesperada. Los Shuar se sentían plenamente autosuficientes y no advertían en lo más mínimo la necesidad de ser "civilizados".

Ya los misioneros de otras Congregaciones y Órdenes se habían topado con un rechazo absoluto y habían acabado renunciando a sus propósitos.

Lo que motivaba a los salesianos no era solo el compromiso contraído con el Gobierno, sino su deseo de evangelizar a una población que permanecía pagana, pero no sabían cómo superar la actitud de un pueblo que no demostraba interés alguno por sus iniciativas.

Es preciso tomar en cuenta también que, mientras tanto, había triunfado la Revolución Liberal y los nuevos gobernantes manifestaban muy poco entusiasmo para admitir la presencia casi exclusiva de unos religiosos, además extranjeros, en una amplia zona del territorio nacional.

La incertidumbre duró décadas y los salesianos no dejaron de hacer intentos para descubrir por dónde podían empezar. Entre el personal que, a causa de las estrictas limitaciones impuestas por los gobernantes, había quedado muy reducido, tomaron cuerpo dos propuestas, no contradictorias, pero bastantes diferentes. Los unos pensaban que tocaba insistir con paciencia, hasta lograr convencer a los Shuar a que permitieran a sus hijitos acercarse a la misión para aprender todas aquellas destrezas que permitían a los blancos disponer de una infinidad de cosas útiles. Dado el sistema de vida shuar que mantiene las viviendas esparcidas en la selva, a notable distancia la una de 
las otras, esta propuesta implicaba que niños y niñas vivieran concentrados en los internados. No fue absolutamente fácil que papás y mamás aceptaran separarse de sus hijos, pero poco a poco la propuesta se abrió camino y por cerca de 50 años una buena parte de la niñez y juventud shuar pasó un tiempo, más o menos largo, en alguna misión. Sobre las ventajas y desventajas del sistema del internado se ha escrito y discutido mucho y no es esta la sede para retomar la polémica.

Otros misioneros, entre ellos el obispo Domingo Comin, manejaban una propuesta diferente. Ellos llegaron a convencerse que solo teniendo delante de los ojos el ejemplo de personas portadoras de una cultura con rasgos cristianos y "civilizados", los Shuar podían emprender el verdadero cambio cultural.

Alrededor de los años 30 del siglo XX hablar del Oriente, para los habitantes de la Sierra, era todavía evocar una realidad envuelta en el misterio y algo amenazante. Fue entonces que un misionero, el p. Albino del Curto, que había emprendido la hazaña de ir a descubrir dónde se encontraba ese Méndez que daba el nombre al Vicariato, dio comienzo a la aventura de abrir un camino de herradura que hiciera accesible la entrada a ese pequeño campamento de mineros que lavaban oro en el Paute. A esa obra dedicó lo mejor de sus años, trabajando personalmente con las cuadrillas de obreros que avanzaban en los flancos del Cerro Negro, rompiendo las rocas y venciendo las resistencias de la selva. El hermano Jacinto Pankeri coronó el proyecto, tendiendo sobre el río Paute el primer puente de cables del Oriente: casi 100 metros de luz.

Desde entonces la corriente de colonos que, saliendo del Azuay y del Cañar, comenzó a afluir hacia el suroriente, no hizo más que engrosar, dando origen a varias poblaciones que hoy son cantones florecientes: Gualaquiza, Limón, Méndez, Sucúa... Pero no pasó mucho tiempo antes que el ojo atento del P. Juan Vigna, párroco en el Pan y después en Macas, advirtiera el serio peligro que se cernía sobre los pobladores shuar, los primeros destinatarios de la actividad salesiana. 
Los colonos pertenecían a una cultura que llevaba siglos de vida sedentaria y de dedicación a la agricultura. Ellos conocían muy bien el valor de un pedazo de terreno, mientras que los Shuar, semi-nómadas, carecían del concepto de la posesión de un área determinada y exclusiva. Apremiados por una necesidad permitían a un colono que se instalara en un lote, pero solo tiempo después se daban cuenta que aquello era irreversible y que no volverían a recuperar la tierra. Así, para sobrevivir, se convertían fácilmente en vaqueros y empleados de los recién llegados.

El P. Vigna adivinó que ese proceso conduciría a una peonización progresiva de los Shuar y durante la primera presidencia de Velasco Ibarra (1934) tomó contacto con el gobierno para frenar esa deriva. Fue en 1945 que se firmó un convenio con la Presidencia de la República, mediante el cual ciertas áreas habitadas por los Shuar se convertían en intangibles: los salesianos serían garantes de que las cláusulas fueran respetadas.

El P. Juan Shutka en 1964 dio un paso más, para obviar la odiosidad que recaía sobre la misión al tener que conservar la integridad de ciertos territorios, dando la impresión que, con el pretexto de defender a los indígenas, se aseguraba la posesión de amplias zonas.

Es así como se fundó en Sucúa la Federación de Centros Shuar con un objetivo muy claro: lograr que los mismos indígenas, conscientes de su fuerza y organizados en una estructura bien definida, en cuanto ciudadanos adultos y responsables, emprendieran la defensa del territorio que les quedaba, de su cultura y de sus derechos.

Se podrá tachar a los salesianos de una actitud errática y algo contradictoria: favorecieron el ingreso de la colonización y al poco tiempo emprendieron iniciativas para frenarla. Pero ver las cosas así equivale a ignorar lo compleja que es la realidad. Una verdadera búsqueda del bien de la gente exige adaptarse a las circunstancias y adivinar lo que es más oportuno en el momento. Las contradicciones están en las situaciones y, sobre todo, en los intereses de las personas. 
De todas maneras, con o sin los misioneros, el choque

entre los colonos y los nativos se habría dado, como en otras zonas del Oriente. La presencia de la misión ha sido más bien un factor que lo ha suavizado. Hoy el Estado es omnipresente y, lo que es lógico, la Iglesia tiene un papel más bien limitado a su misión específica.

Los colonos son muy numerosos y, para muchos, se trata de la tercera y cuarta generación. De ninguna manera se consideran advenedizos o invasores. Al mismo tiempo los Shuar han tomado una conciencia clarísima de sus derechos y de los peligros que los amenazan.

No existen fórmulas fijas, ni soluciones definitivas: las que en un momento se las ve como las más convenientes, después pueden recibir una valoración diferente, porque han sobrevenido nuevos factores que han alterado el panorama.

Un tiempo los internados fueron alabados por todos, empezando por personal del Gobierno y por la opinión pública, pero después recibieron una avalancha de críticas.

La iniciativa de los salesianos de abrir un camino de penetración al Oriente recibió aplausos de las autoridades del Azuay y, obviamente, fue bendecida por los colonos, pero no faltaron en aparecer apreciaciones opuestas, hasta de parte de no pocos salesianos.

La misma Federación de Centros Shuar fue ensalzada por algunas de sus actuaciones y criticada por otras. Hubo un momento en que, para obtener el título de propiedad de la tierra, no era suficiente demostrar que se la habitaba desde tiempos inmemorables, sino que era indispensable destruir la selva. En aquel entonces la consigna: "La tierra a quien la trabaja" era un dogma indiscutible y entonces se hizo un gran esfuerzo para introducir la ganadería. La Federación se empeñó a fondo en este programa. No pasó mucho tiempo y los ecólogos echaron por los suelos el entusiasmo que se había despertado, proclamando que el ganado es el destructor más eficaz de la frágil capa de humus de la selva y había que sustituirlo con otras iniciativas. 
Nunca toca escoger simplemente entre blanco y negro, casi siempre las situaciones son grises y ambiguas.

No hay que permitir que esto paralice cualquier emprendimiento: se interviene y se asumen las responsabilidades. Cuando se descubre que la dirección debe corregirse, se corrige y se sigue adelante. Quien teme ser criticado acaba negándose a meter mano a cualquier actividad. Pero esta actitud es la que merece las mayores críticas. 